\title{
The Incidence, Risk Factors, and Clinical Outcomes for Endovenous Heat-induced Thrombosis after Radiofrequency Ablation
}

\author{
Geunhyeok Yang, Sungsin Cho, Jin Hyun Joh \\ Department of Surgery, Kyung Hee University Hospital at Gangdong, Kyung Hee University School of Medicine, Seoul, Korea
}

Received October 10, 2019 Revised November 18, 2019 Accepted November 26, 2019
Correspondence to: Jin Hyun Joh

Department of Surgery, Kyung Hee University Hospital at Gangdong, Kyung Hee University School of

Medicine, 892 Dongnam-ro,

Gangdong-gu, Seoul 05278, Korea

Tel: $+82-2-440-6261$

Fax: + 82-2-440-6296

E-mail: jhjoh@khu.ac.kr
Purpose: Endovenous radiofrequency ablation (RFA) is a safe, effective treatment for varicose veins caused by saphenous reflux. Endovenous heat-induced thrombosis (EHIT) is a unique complication for this procedure. This study evaluated the incidence, risk factors, and clinical consequences of EHIT.

Methods: We retrospectively reviewed the data of patients with varicose veins who underwent radiofrequency ablation (RFA). Duplex ultrasonography (DUS) was performed within 1 week and then 6 months after the procedure. If EHIT was found at the first postprocedural DUS, then monthly surveillance was done. The incidence of EHIT and the risk factors were analyzed. The clinical consequence was finally investigated.

Results: During the study period, a total of 1,247 saphenous veins in 783 patients underwent RFA. Four hundred fifty-seven (58.4\%) patients were women. The mean age was $52.9 \pm$ 12.4 years (range: $8-85$ years). EHIT was present in 7 (0.6\%) saphenous veins in 7 (0.9\%) patients. EHIT developed in 6 great saphenous veins (GSV) and 1 small saphenous vein. EHIT class I, II, and III were 3, 2, and 2 patients, respectively. The diameter of GSV $\geq 6 \mathrm{~mm}$ was the significant risk factor for the occurrence of EHIT. Six EHITs spontaneously resolved within 5 weeks after the procedure. One EHIT was resolved in 7 months after the procedure. No incidences of pulmonary embolism occurred.

Conclusion: EHIT was a rare complication after RFA. Moreover, it spontaneously resolved without any clinical sequelae. Thus, performing routine DUS is not recommended to evaluate EHIT in the asymptomatic patient.

Keywords: Varicose vein, Endovascular, Thrombosis, Ultrasonography, Risk factor

\section{INTRODUCTION}

Varicose veins has high prevalence. The reported incidence of varicose vein ranges from $1 \%$ to $73 \%$ for females and $2 \%$ to $56 \%$ in males. (1) It is part of chronic venous disease, which is reported to have a substantial negative impact on health-related qual- ity of life. (2) Before the worldwide spread of endovenous therapy, high ligation and stripping of the saphenous vein has been the standard treatment for patients with varicose vein. Nowadays, the endovenous ablation procedures are the most used techniques for the treatment of chronic venous insufficiency. (3) 
Radiofrequency ablation (RFA) is a safe and effective treatment for varicose veins. The RFA showed less periprocedural pain and bruising compared with endovenous laser therapy (EVLT).(4,5) Long-term results have been shown to be equal to those obtained with conventional surgical treatment, while providing faster recovery, less pain, and a better quality of life. $(6,7)$

Endovenous heat-induced thrombosis (EHIT) is a worrisome complication of this procedure. Thrombotic complications after RFA have been classified 2 main categories: deep venous thrombosis (DVT) and EHIT. It is a prvoked phenomenon. Indeen it occurs in a very short time soon after a planned and controlled injury of a selected length of the vein opposed to a spontaneous thrombosis which occurs instead in a unpredictable way and in segments not generally continuous. (8) The purpose of this study is to report the incidence, clinical consequence, and risk factors of EHIT after RFA for the varicose vein with larger volume of patients.

\section{METHODS}

A retrospective analysis was performed using clinical data of the patients who underwent RFA. Patients were underwent duplex scan at the out patient department and taken history, physical examination.

Ultrasound examination was done with a colorized duplex scan (Vivid E9 Ultrasound system; GE Healthcare, Waukesha, WI, USA). The diameters of the great saphenous vein (GSV) and the small saphenous vein (SSV) were measured in supine position. With B-mode imaging, the inner anechoic diameter of the GSV was measured from the saphenofemoral junction (SFJ) to $5 \mathrm{~cm}$ distal to the junction. The SSV diameter was measured in the same manner from the saphenopopliteal junction (SPJ) to $5 \mathrm{~cm}$ distal to the junction. The largest diameter was chosen to analyze the relationship between diameter and stump length. After evaluation of the diameter, SFJ, SPJ, and truncal vein reflux in response to a Valsalva's maneuver and/or manual distal compression followed by release with upper body elevation or with standing position were identified with duplex scanning. The saphenous reflux was defined as a reflux time $\geq 0.5$ second.

The RFA procedure was performed under general or spinal anesthesia at the operating room in all patients. Concurrent high ligation of the saphenous vein was not performed in our center. A phlebectomy around and below knee joint was performed simultaneously if indicated. RFA using ClosureFast $^{\mathrm{TM}}$ (Covidien, Mansfield, MA, USA) catheter was done according to the manufacturer's instructions for use. The treatment consisted of segmental heating of the great saphenous vein (GSV), small saphenous vein (SSV) or accessory saphenous vein using a catheter with a $7-\mathrm{cm}$ heating element. To reduce EHIT at GSV, the catheter was advanced to $2 \mathrm{~cm}$ below the saphenofemoral or saphenopopliteal junction under ultrasound guidance. If there is deep vein confluence with SSV, ablation was performed $2 \mathrm{~cm}$ distal from the confluence, and if there is no deep vein confluence, ablation was started from the fascial level at SSV. About $10 \mathrm{~mL}$ of tumescent solution (normal saline) per one centimeter of truncal vein was injected around the vein before the start of ablation for tissue protection. The temperature of the element was maintained at $120^{\circ} \mathrm{C}$ for 20 seconds per segment using a thermocouple on the heating element, which provided a feedback loop to the generator during withdrawal. Double ablation of the most proximal segment was performed. If the incompetent perforating vein was present at the ablated segment, double treatment was done. External compression of the treated segment was applied using a surgical towel. At the completion of procedure, all wounds were dressed with steri-strips or histoacryl agent and legs 
were placed in fullength cohesive elastic bandage (Karl Otto Braun GmbH \& Co, Wolfstein, Germany) or Rosidal CC (Lohmann \& Rauscher). The bandage was exchanged for thigh-length compression stocking after 24 hours. Patients was advised to wear this stocking for a minimum of 2 weeks. Patients were discharged on the postoperative day one with a stocking.

Patients were followed up at 1 week and 1, 6 months after surgery. At all subsequent visits, the patients were examined clinically and with duplex scanning. At 1 week, duplex scanning was performed to confirm saphenous vein occlusion and to evaluate any complications such as deep vein thrombosis, hematoma, EHIT, or any complications related with surgery. At 1,6 months, a further duplex scan was performed to evaluate any complications if EHIT was detected on the initial duplex scanning.

The incidence of EHIT was evaluation. Risk factors assessed for the development of EHIT included demo- graphic data, saphenous vein diameter, operation time, amount of tumescent solution, number of phlebectomy. The natural course of EHIT was elucidated.

Statistical analysis was done using independent t-test for comparison of continuous variables and Fisher's exact test for comparison of nominal variables. All $\mathrm{P}$ values were 2 -tailed, and $\mathrm{P}<0.05$ was considered to be statistically significant.

\section{RESULTS}

During the study period, a total of 1,247 saphenous veins in 783 patients were performed RFA. Patient demographics are shown in Table 1. The mean age was $52.9 \pm 12.4$ years with a range of 8 to 84 years. The female to male ratio was 457:326. The most common symptom related with varicose vein was heaviness followed by night cramping, discomfort, pain, swelling, costmetic conern and itching.

Table 1. Patient Demographics

\begin{tabular}{lc}
\hline \multicolumn{1}{c}{ Demographics } & $\mathrm{N}=783(\%)$ \\
\hline Age (year) mean \pm SD (range) & $52.9 \pm 12.4(8-84)$ \\
Sex (male:female) & $326(41.6 \%): 457(58.4 \%)$ \\
Indication for treatment, $\mathrm{n}(\%)$ & $427(54.5)$ \\
Heaviness & $401(51.2)$ \\
Night cramping & $351(44.8)$ \\
Discomfort & $167(21.3)$ \\
Pain & $62(7.9)$ \\
Swelling & $45(5.7)$ \\
Cosmetic concern & $10(1.3)$ \\
Itching & 1,128 \\
Limbs & $201(25.7): 237(30.3): 345(44.1)$ \\
Right:Left:Bilateral & 1,247 \\
Truncal veins & $405(51.7): 311(39.7): 48(6.1): 19(2.4)$ \\
1:2:3:4 & $10(1.3)$ \\
Anesthesia, $n(\%)$ & $19(2.4)$ \\
Local & $543(69.3)$ \\
MAC & $211(26.9)$ \\
Spinal & $333.5 \pm 142.2(40-800)$ \\
General & $7.1 \pm 6.28(0-35)$ \\
Tumescent solution (ml), mean \pm SD (range) &
\end{tabular}

$\mathrm{SD}=$ standard deviation; $\mathrm{MAC}=$ monitored anesthesia care. 
Bileteral ablation was done in 345 patients. RFA was done simultaneously if the GSV and SSV in the same leg showed refluxes of $\geq 0.5$ second. In one session, one truncal vein was ablated in 405 patients, 2 truncal veins in 311 patients, and 3 truncal veins in 48 patients. Four truncal veins were ablated simultaneously in 19 patients. The mean injected tumescent solution was $333.5 \mathrm{~mL}$. The phlebectomy for the dilated vein was done simultaneous. The mean number of phlebectomy was 7.1.

EHIT detected by postoperative duplex scanning in 7 patients (0.6\%). Postoperative duplex scanning revealed class 1 EHIT in 3 patients, class 2 EHIT in 2patients, and class 3 EHIT in 2 patients. All EHIT was spontaneously resoluved at 5 weeks except one patient as shown in Fig. 1. In one patient, EHIT was resolved at 6 months (Table 2). Anticoagulation was not used in all patient with EHIT. The evaluation of pulmonary embolism was not performed because of no symptom related with it.

The clinical characteristics of the patient with and without EHIT was shown in Table 3. The comorbidies, ablation side and treated saphenous vein, or presence of symptom of two groups were similar. The significant risk factor for the development of EHIT was the diameter of GSV $\geq 6 \mathrm{~mm}$ (Table 4 ).

\section{DISCUSSION}

This study showed that the incidence of EHIT after RFA was $0.6 \%$. The extruded thrombus into the deep vein was slowly retracted toward the saphenous vein. EHIT was typically resolved after 5 weeks after RFA. In one patient, EHIT lasted until 6 months. The diameter of GSV $\geq 6 \mathrm{~mm}$ was the only significant risk factor for the development of EHIT.

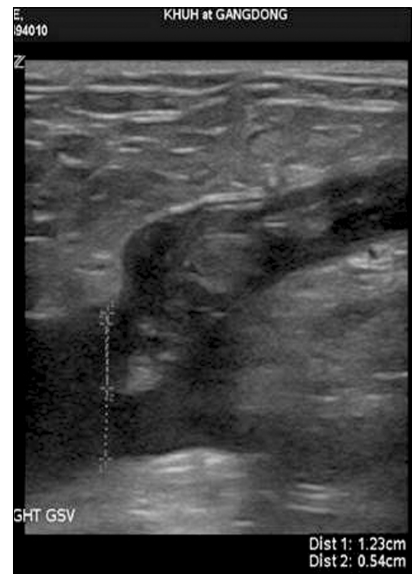

1 week

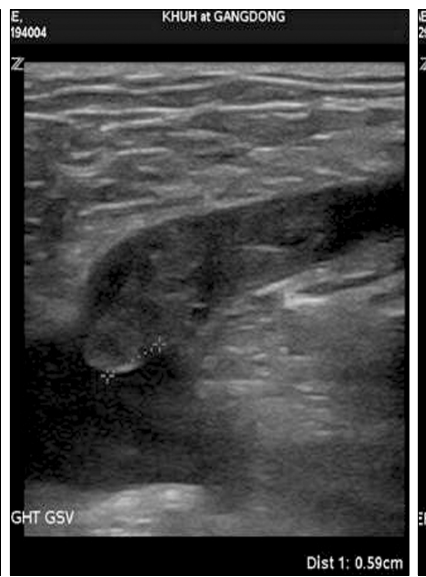

5 weeks

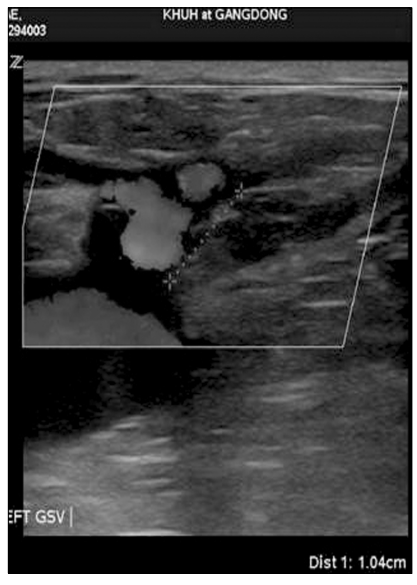

6 months
Fig. 1. The natural course of endovenous heat-induced thrombosis The extension of thrombus into the deep vein on one week was slightly retracted on 5 weeks then, resolved on 6 months.

Table 2. Natural Course of Endovenous Heat-Induced Thrombosis

\begin{tabular}{clcclc}
\hline No & Age/Sex & Ablation & Class & Course & PE symptom \\
\hline 1 & $39 /$ male & GSV & 1 & Resolved at 5 weeks & None \\
2 & $38 /$ female & GSV & 1 & Resolved at 5 weeks & None \\
3 & $66 /$ male & GSV & 3 & Resolved at 5 weeks & None \\
4 & $45 /$ female & GSV & 3 & Resolved at 5 weeks & None \\
5 & $67 /$ female & GSV & 2 & Resolved at 5 weeks & None \\
6 & $64 /$ male & GSV & 2 & Resolved at 6 months & None \\
7 & $64 /$ female & SSV & 1 & Resolved at 5 weeks & None \\
\hline
\end{tabular}

$\mathrm{GSV}=$ great saphenous vein; SSV = small saphenous vein; $\mathrm{PE}=$ pulmonary embolism. 
Table 3. Clinical Characteristics of Patient with/without Endovenous Heat-Induced Thrombosis

\begin{tabular}{|c|c|c|c|}
\hline Risk factors & EHIT (-) & $\operatorname{EHIT}(+)$ & P value* \\
\hline Patients & 776 & 7 & \\
\hline Age (year), mean \pm SD & $52.8 \pm 12.5$ & $51.0 \pm 14.4$ & 0.754 \\
\hline BMI $\left(\mathrm{kg} / \mathrm{m}^{2}\right)$ mean $\pm \mathrm{SD}$ & $24.8 \pm 3.6$ & $22.3 \pm 2.3$ & 0.170 \\
\hline Gender, n (\%) & & & 1.000 \\
\hline Female & $297(57.2)$ & $4(57.1)$ & \\
\hline Male & $222(42.8)$ & $3(42.9)$ & \\
\hline Side, $\mathrm{n}(\%)$ & & & 0.328 \\
\hline Right & $198(25.5)$ & $3(42.9)$ & \\
\hline Left & $236(30.4)$ & $1(14.2)$ & \\
\hline Bilateral & $342(44.1)$ & $3(42.9)$ & \\
\hline Treated vein, n (\%) & & & 0.594 \\
\hline GSV & $541(69.7)$ & $5(71.4)$ & \\
\hline SSV & $101(13.0)$ & 0 & \\
\hline Both & $134(17.3)$ & $2(28.6)$ & \\
\hline \multicolumn{4}{|l|}{ Comorbidities, n (\%) } \\
\hline History of DVT, n (\%) & $2(0.3)$ & 0 & 1.000 \\
\hline Aspirin, n (\%) & $29(3.7)$ & 0 & 1.000 \\
\hline Smoking, n (\%) & $39(5.0)$ & 0 & 1.000 \\
\hline Diabetes, n (\%) & $39(5.0)$ & 0 & 1.000 \\
\hline Hypertension & $90(11.6)$ & 0 & 0.594 \\
\hline Presence of symptom, n (\%) & $371(47.8)$ & $2(28.6)$ & 0.147 \\
\hline
\end{tabular}

EHIT = endovenous heat-induced thrombosis; SD = standard deviation; BMI = body mass index; GSV = great saphenous vein; SSV = small saphenous vein; DVT $=$ deep vein thrombosis.

*Statistical analysis was done using independent t-test for comparison of continuous variables and Fisher's exact test for comparison of nominal variables.

Table 4. Analysis of Risk Factors of Endovenous Heat-Induced Thrombosis

\begin{tabular}{|c|c|c|c|c|}
\hline Risk factors & Number & $\begin{array}{c}\text { EHIT (-) } \\
\text { Number (\%) }\end{array}$ & $\begin{array}{c}\text { EHIT (+) } \\
\text { Number (\%) }\end{array}$ & P value* \\
\hline GSV diameter & 527 & $\mathrm{n}=521$ & $\mathrm{n}=6$ & 0.008 \\
\hline$<6 \mathrm{~mm}$ & & $291(55.9)$ & 0 & \\
\hline$\geq 6 \mathrm{~mm}$ & & $230(44.1)$ & $6(100)$ & \\
\hline Operation time & 524 & $\mathrm{n}=519$ & $\mathrm{n}=5$ & 1.000 \\
\hline$<60 \min$ & & $303(58.4)$ & $3(60)$ & \\
\hline$\geq 60 \min$ & & $216(41.6)$ & $2(40)$ & \\
\hline Tumescent solution & 311 & $\mathrm{n}=307$ & $\mathrm{n}=4$ & 0.230 \\
\hline$<300 \mathrm{~mL}$ & & $70(22.8)$ & $2(50)$ & \\
\hline$\geq 300 \mathrm{~mL}$ & & $237(77.2)$ & $2(50)$ & \\
\hline Number of phlebectomy & 281 & $\mathrm{n}=276$ & $\mathrm{n}=5$ & 0.652 \\
\hline$<5$ & & $108(39.1)$ & $1(20)$ & \\
\hline$\geq 5$ & & $168(60.9)$ & $4(80)$ & \\
\hline
\end{tabular}

EHIT $=$ endovenous heat-induced thrombosis, Fisher's exact test.

*Statistical analysis was done using Fisher's exact test.

The reported incidence of EHIT was various. This rate was lower than the rates reported by Sufian and colleagues (1.3\%) (9) and Nuttawut and colleagures (7\%) (10) and lower than the rate reported by Marsh and colleagues (0.2\%).(11) Interestingly, some previous studies reported a decrease in the incidence of EHIT that was commensurate with increases in the number of RFA procedures performed by an in- 
dividual surgeon. $(11,12)$

In our study, the larger diameter of GSV $\geq 6 \mathrm{~mm}$ was the only significant risk factor for the development of EHIT. This finding was consistent with the reported findings from a study by Sufian and colleagues. (9) The etiology behind why a large vein diameter is associated with higher rates of EHIT rates remains unclear. Kane et al. (13) reported that in a large vein, incomplete closure near the SFJ might occur, which may facilitate stasis of venous flow near the thermally damaged endothelium that allows a thrombus to develop and propagate into the CFV.

The pathogenesis of EHIT was unclear. But it differs markedly from that of standard deep venous thrombosis. It is characterized by adherence to the vein wall and relatively early resolution, and may not cause pulmonary embolism (PE).(14) Some authors prefer the acronym PASTE (postablation superficial thrombus extension) to the term EHIT because nothing indicates that heat application is responsible for thrombus propagation. (15)

In this study, all EHIT's were spontanouely regressed. We confirmed that most cases of EHIT disappeared spontaneously within 5 weeks except one case whose EHIT was regressed at 6 months. Marsh and colleagues use the single dose of prophylactic lower molecular-weighed heparin (LMWH).(11) Failure of this strategy for prophylaxis has been reported in patients with a history of venous thromboembolism (VTE).(16,17) Preoperative use of anticoagulation might not be recommended due to interference with thrombotic vessel occlusion. (18) The risk of PE from EHIT remains undefined and is uncommon after open varicose vein surgery. (19) We are unaware of any reports of patients with $\mathrm{PE}$ directly in association with isolated EHIT.

\section{CONCLUSION}

The EHIT is a rare complication after RFA. It was spontaneously resolved without any clinical symptom. Thus, it may be suggested against routine duplex scanning to evaluate EHIT at postoperative period in asymptomatic patients.

\section{CONFLICT OF INTEREST}

None.

\section{REFERENCES}

1. Lohr J, Kulwicki A. Radiofrequency ablation: evolution of a treatment. Semin Vasc Surg 2010;23:90-100.

2. Carroll C, Hummel S, Leaviss J, Ren S, Stevens JW, Everson-Hock E, et al. Clinical effectiveness and cost-effectiveness of minimally invasive techniques to manage varicose veins: a systematic review and economic evaluation. Health Technol Assess 2013;17: i-xvi, 1-141.

3. Kim J, Cho S, Joh JH, Ahn HJ, Park HC. Effect of diameter of saphenous vein on stump length after radiofrequency ablation for varicose vein. Vasc Specialist Int 2015;31:125-9

4. Shepherd AC, Gohel MS, Brown LC, Metcalfe MJ, Hamish M, Davies AH. Randomized clinical trial of VNUS ClosureFAST radiofrequency ablation versus laser for varicose veins. Br J Surg 2010;97:810-8.

5. Goode SD, Chowdhury A, Crockett M, Beech A, Simpson R, Richards $\mathrm{T}$, et al. Laser and radiofrequency ablation study (LARA study): a randomised study comparing radiofrequency ablation and endovenous laser ablation $(810 \mathrm{~nm})$. Eur J Vasc Endovasc Surg 2010;40:246-53.

6. Lurie F, Creton D, Eklof B, Kabnick LS, Kistner RL, Pichot $\mathrm{O}$, et al. Prospective randomized study of endovenous radiofrequency obliteration (closure procedure) versus ligation and stripping in a selected patient population (EVOLVeS Study). J Vasc Surg 2003; 38:207-14.

7. Lurie F, Creton D, Eklof B, Kabnick LS, Kistner RL, Pichot $\mathrm{O}$, et al. Prospective randomised study of endovenous radiofrequency obliteration (closure) versus ligation and vein stripping (EVOLVeS): two-year follow-up. Eur J Vasc Endovasc Surg 2005;29:67-73.

8. Sufian S, Arnez A, Labropoulos N, Lakhanpal S. Endovenous heat-induced thrombosis after ablation with $1470 \mathrm{~nm}$ laser: incidence, progression, and risk factors. Phlebology 2015;30:325-30.

9. Sufian S, Arnez A, Labropoulos N, Lakhanpal S. Incidence, progression, and risk factors for endovenous heat-induced thrombosis after radiofrequency 
ablation. J Vasc Surg Venous Lymphat Disord 2013;1: 159-64.

10. Sermsathanasawadi N, Pitaksantayothin W, Puangpunngam N, Chinsakchai K, Wongwanit C, Mutirangura $\mathrm{P}$, et al. Incidence, risk factors, progression, and treatment of endovenous heat-induced thrombosis Class 2 or greater after endovenous radiofrequency ablation. Dermatol Surg 2019;45:573-80.

11. Marsh P, Price BA, Holdstock J, Harrison C, Whiteley MS. Deep vein thrombosis (DVT) after venous thermoablation techniques: rates of endovenous heat-induced thrombosis (EHIT) and classical DVT after radiofrequency and endovenous laser ablation in a single centre. Eur J Vasc Endovasc Surg 2010;40:521-7.

12. Sadek M, Kabnick LS, Rockman CB, Berland TL, Zhou $\mathrm{D}$, Chasin $\mathrm{C}$, et al. Increasing ablation distance peripheral to the saphenofemoral junction may result in a diminished rate of endothermal heat-induced thrombosis. J Vasc Surg Venous Lymphat Disord 2013; $1: 257-62$.

13. Kane K, Fisher T, Bennett M, Shutze W Jr, Hicks T, Grimsley B, et al. The incidence and outcome of endothermal heat-induced thrombosis after endovenous laser ablation. Ann Vasc Surg 2014;28:1744-50.

14. Frasier K, Latessa V. Minimally invasive vein therapy and treatment options for endovenous heat-induced thrombus. J Vasc Nurs 2008;26:53-7.

15. Jones RT, Kabnick LS. Perioperative duplex ultrasound following endothermal ablation of the saphenous vein: is it worthless? J Invasive Cardiol 2014;26: $548-50$.

16. van Rij AM, Chai J, Hill GB, Christie RA. Incidence of deep vein thrombosis after varicose vein surgery. Br J Surg 2004;91:1582-5.

17. Enoch S, Woon E, Blair SD. Thromboprophylaxis can be omitted in selected patients undergoing varicose vein surgery and hernia repair. Br J Surg 2003;90: 818-20.

18. Gibson KD, Ferris BL, Polissar N, Neradilek B, Pepper D. Endovenous laser treatment of the small [corrected] saphenous vein: efficacy and complications. J Vasc Surg 2007;45:795-801; discussion 801-3.

19. Bounameaux H, Huber O. Postoperative deep vein thrombosis and surgery for varicose veins. BMJ 1996;312:1158. 